\title{
Dynamic hydraulic jump and retrograde sedimentation in an open channel induced by sediment supply: experimental study and SPH simulation
}

\author{
Xiaogang Zheng', Ridong Chen', Min Luo ${ }^{2}{ }^{\dagger}$, Ehsan Kazemi ${ }^{3}$ and Xingnian Liu ${ }^{1}$
}

\begin{abstract}
${ }_{1}^{1}$ State Key Laboratory of Hydraulics and Mountain River Engineering, Sichuan University, Chengdu 610o65, China 2 Zienkiewicz Centre for Computational Engineering, College of Engineering, Swansea University, SA1 8EN, United Kingdom 3 Department of Civil and Structural Engineering, University of Sheffield, Sheffield S1 3JD, United Kingdom
\end{abstract}

+Corresponding Author, Email: min.luo@swansea.ac.uk

\begin{abstract}
Mountainous torrents often carry large amounts of loose materials into the rivers, thus causing strong sediment transport. Experimentally it was found for the first time that when the intensive sediment motion occurs downstream over a gentle slope, the siltation of the riverbed is induced and the sediment particles can move upstream rapidly in the form of a retrograde sand wave, resulting in a higher water level along the river. To further study the complex mechanisms of this problem, a sediment mass model in the framework of the Smoothed Particle Hydrodynamics (SPH) method was presented to simulate the riverbed evolution, sediment particle motion, and the generation and development of dynamic hydraulic jump under the condition of sufficient sediment supply over a steep slope with varying angles. Because the sediment is not a continuous medium, the marker particle tracking approach was proposed to represent a piece of sediment with a marked sediment particle. The two-phase SPH model realizes the interaction between the sediment and fluid by moving the bed boundary particles up and down, so it can reasonably treat the fluidsediment interfaces with high CPU efficiency. The critical triggering condition of sediment motion, the propagation of the hydraulic jump and the initial siltation position were all systematically studied. The experimental and numerical results revealed the extra disastrous sediment effect in a mountainous flood. The findings will be useful references to the disaster prevention and mitigation in mountainous rivers.
\end{abstract}

Keywords: Dynamic hydraulic jump; retrograde sedimentation; sediment supply; mountainous river; Smoothed Particle Hydrodynamics; marked sediment particle

\section{Introduction}

The terrains of the mountain and gorge are quite complex, characterized by the high-speed flow confluence, abrupt flood level fluctuation, multiple stage-discharge relation and intensive sediment transport capacity. Under the influence of heavy rain, the rapid runoff often forms mountain torrents and carries a large amount of sediment, thus inducing severe sediment disasters. In the past, researches on the mechanism of mountain torrents focused on the effect of discharge surge caused by the confluence in mountainous rivers (Guillén-Ludeña et al. 2016). However, later investigations revealed that even though the flood discharge did not exceed the standard level, river flooding disasters still occurred. This was caused by the sedimentation and the riverbed elevation, thus made the water level exceed the flood control standard. For example, in June 2000, under the influence of a two-year occurrence flood in Polo Power Station in Sichuan Province, China, the water level exceeded the embankments that were designed on the 50-year occurrence flood discharge (Chen et al. 2015). A more recent mountain torrent disaster, as shown in Figure 1, occurred in Liangshan City of China. Two erosion ditches appeared in the upper mountain of the village. As for the right erosion ditch, both sides of the gully were protected by the vegetation that prevented a large amount of sediment from entering the downstream area. The vegetation covering on the left erosion ditch was, however, very poor so quite a few sediment materials entered the gully following the river confluence. Under the same rainfall condition, the flood occurred with a low discharge in the mild downstream channel and inundated the residential area due to the sedimentation and flow-retardation in the left erosion ditch. One typical feature of the two disasters is that the sediment was transported downstream and changed the riverbed morphology there, resulting in the real water level being many times higher than the predicted one in the river. Therefore, it seems necessary to study the mountain torrents by considering the extra sediment effect in the sediment supply region (Pitlick et al. 2013). 


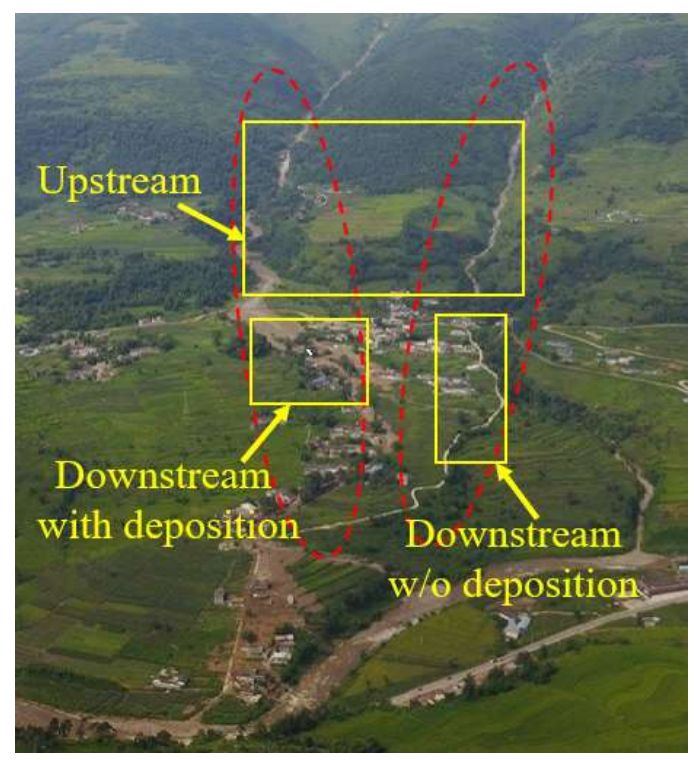

Figure 1 Mountain torrent disaster in Liangshan City, China

With the rapid development in computer technology, researchers have conducted a large number of numerical studies on the mountain torrents. The numerical methods are based primarily on the Eulerian grid, such as finite element, finite volume and finite difference approaches (Liang and Borthwick 2009; Xia et al. 2011; Guo et al. 2012). Although these numerical techniques exhibit good advantages such as high CPU efficiency and realistic simulation results, the grid-based models can be cumbersome while handling the large deformation of free surface and fluid-sediment interface problems. In addition, these grid methods cannot accurately simulate the sediment particles naturally, therefore, the diffusion equation has to be used to approximate the distribution of sediments (Zhu et al. 2013).

In recent years, the mesh-free particle methods that do not require any grid have been developed rapidly. The particle schemes discretize the continuum using the particles rather than the meshes in the spatial domain. The advantage is that the computational domain can easily distort and deform so as to simulate many types of free surface flows with large interface deformation and fragmentation (Liu and Liu 2004). One of the popular particle methods is the Smoothed Particle Hydrodynamics (SPH) method (Monaghan 1994), which has been extensively used in various hydrodynamic fields such as the free surface flow (Zhang and Liu 2018), non-Newtonian flow (Hosseini et al. 2007; Shao and Lo 2003), flowrigid body interactions (Sun et al. 2015), hydraulic jump (De Padova et al. 2013; De Padova et al. 2017; Federico et al. 2012; Jonsson et al. 2016; López et al. 2010) and fluid-sediment problems such as the sediment erosion (Khanpour et al. 2016) and transport (Nabian and Farhadi 2016). Some recent SPH works have described a procedure to filter the high-frequency oscillations in the pressure field given by the use of an artificial speed of sound in the case of strong dynamics (Meringolo et al. 2017) and slow dynamics (Aristodemo et al. 2017). This is an improvement of some diffusive approaches (Antuono et al. 2010) in which the numerical noise is just alleviated. For the SPH simulation of sediment problems, two main strategies are adopted. One approach is to treat the water and sediment as two different phases with different densities and viscosities and both phases of the particles are involved in the SPH derivative computations (Gotoh and Khayyer 2018). Sometimes a non-Newtonian constitutive model is used to predict the pressure-based viscosity of the solid phase in order to solve the discontinuities of flow variables at the water-sediment interface (Shakibaeinia and Jin 2011). This modeling approach is straightforward to use by solving a unified set of SPH equations without extra numerical algorithms, however, there is no vigorous sediment initiation and transport mechanism involved. Another approach would be more realistic, i.e. to consider the critical pick-up velocity (Hayashi et al. 2003) and shear stress (Manenti et al. 2012; Wang et al. 2018) of the fluid flow acting on the sediment boundary, and treat the bed boundary as a movable and soluble solid wall. For this type of the sediment model, when the velocity or shear stress of the fluid flow exceeds the critical value, the sediment particles will move in a pseudo-fluid manner according to the SPH equations of motion. However, for practical engineering application, the present sediment incipience model must be further improved and more mature sediment deposition model should also be developed.

The second approach as mentioned above will be used in this study as it can more realistically reflect the sediment erosion and scouring mechanisms that are widely adopted in the engineering field. To enrich the application of SPH model in simulating the dynamic hydraulic jump in open channels, a Weakly Compressible SPH (WCSPH) model is used to simulate the flow motions. Fluid is a continuous 
medium so a fluid particle can represent the surrounding fluids. However, a sediment particle cannot represent the surrounding sediment because sediment is not a continuous medium. Therefore, the marker sediment method is proposed to represent the surrounding layer of sediment with a marked sediment particle. By using this algorithm, the role of a large amount of sediment particles in other numerical models can be represented by one marked sediment particle in this model, thus reducing the number of sediment particles involving calculation, improving the CPU efficiency and making the model more practical in engineering applications.

The paper is structured as follows. Firstly, the principles of the SPH method and the treatment of boundary conditions are introduced. Subsequently, the water-sediment interaction strategy is proposed and the sediment transport and riverbed evolution models are developed. Following this, the model is validated by reproducing the benchmark test of dam break flow over a movable sediment bed. Then, a series of laboratory sediment transport experiments were performed in a steep slope channel with varying angles. In the model applications, the SPH numerical simulations were performed to study the effects of sediment intensity and inflow discharge on the propagation of dynamic hydraulic jump waves, the sediment movement characteristics, the fundamental mechanisms of retrograde development and critical triggering condition of the sedimentation.

\section{SPH Fluid Model}

\subsection{Governing equations}

The SPH model solved the Navier-Stokes (N-S) equations in the Lagrangian form as follows (Liu and Liu 2004):

$$
\begin{gathered}
\frac{1}{\rho} \frac{D \rho}{D t}+\nabla \cdot \mathbf{u}=0 \\
\frac{D \mathbf{u}}{D t}=-\frac{1}{\rho} \nabla P+\mathbf{g}+\boldsymbol{\Theta}
\end{gathered}
$$

where $\rho=$ fluid particle density; $t=$ time; $\mathbf{u}=(u, v)$ particle velocity vector; $P=$ particle pressure; $\mathbf{g}=$ gravitational acceleration vector; and $\boldsymbol{\Theta}=$ diffusion term.

The fluid in the SPH formalism is treated as weakly compressible. Using an equation of state can relate the density change to the fluid pressure as (Monaghan 1994):

$$
P=B\left[\left(\frac{\rho}{\rho_{0}}\right)^{\kappa}-1\right]
$$

where $\kappa=7 ; \rho_{0}=1000 \mathrm{~kg} / \mathrm{m}^{3}$, which is the initial density of fluid; and constant $B$ is calculated as $B=c^{2} \rho_{0} / \kappa$, where $c=10 \times V_{\max }$ is the nominal value of the chosen sound speed and $V_{\max }$ is the largest fluid particle velocity.

\subsection{SPH particle approximations}

The fluid density of particle $i, \rho_{i}$, is evaluated by its neighbouring particles $j$ as follows:

$$
\rho_{i}=\sum_{j} m_{j} W\left(\left|\mathbf{r}_{i}-\mathbf{r}_{j}\right|, h\right)
$$

where $m=$ particle mass; $\mathbf{r}=$ particle position vector; $h=$ smoothing length; and $W=$ kernel weighting function. The spline-based kernel for a 2D system (Monaghan 1994) is used here:

$$
W(r, h)= \begin{cases}\frac{10}{7 \pi h^{2}}\left(1-\frac{3}{2} Q^{2}+\frac{3}{4} Q^{3}\right) & 0 \leq Q \leq 1 \\ \frac{10}{28 \pi h^{2}}(2-Q)^{3} & 1 \leq Q \leq 2 \\ 0 & Q \geq 2\end{cases}
$$


where $Q=r / h$; and $r=$ the distance from the reference particle to a neighbor particle. To balance the computational accuracy and efficiency, $h$ is selected to be $1.2 l_{o}\left(l_{o}=\right.$ the initial particle spacing) in this study.

The pressure gradient term is computed as follows:

$$
\left(\frac{1}{\rho} \nabla P\right)_{i}=\sum_{j} m_{j}\left(\frac{P_{i}}{\rho_{i}^{2}}+\frac{P_{j}}{\rho_{j}^{2}}\right) \nabla_{i} W_{i j}
$$

where the summation is over all the particles other than particle $i$ and the sediment particles; and $\nabla_{i} W_{i j}$ $=$ gradient of the kernel with respect to the position of particle $i$.

The diffusion term is the laminar viscosity term, in Equation (2), expressed as follows:

$$
\boldsymbol{\Theta}_{i}=\sum_{j} m_{j}\left(\frac{4 v_{0} \mathbf{r}_{i j} \nabla_{i} W_{i j}}{\left(\rho_{i}+\rho_{j}\right)\left|\mathbf{r}_{i j}\right|^{2}}\right) \mathbf{u}_{i j}
$$

where $v_{0}=10^{-6} \mathrm{~m}^{2} / \mathrm{s}$ is the kinematic viscosity of laminar flow; $\mathbf{r}_{i j}=\mathbf{r}_{i}-\mathbf{r}_{j} ;$ and $\mathbf{u}_{i j}=\mathbf{u}_{i}-\mathbf{u}_{j}$.

\subsection{Boundary conditions}

\subsubsection{Wall boundary}

The wall boundary is simulated by fixed (zero velocity) wall particles on the physical wall and two layers of fixed dummy particles that locate outside of the physical wall (Koshizuka et al. 1998). The wall particles satisfy the same mass equation as the fluid particles so that their density and pressure are updated, but the position and velocity of these particles remain unchanged. This boundary treatment ensures that the influence domain of the fluid particles near the wall is not truncated and prevents the fluid particles from penetrating the wall due to the pressure gradient produced at these fixed particles.

\subsubsection{In/out flow boundary}

The key to simulate an open-channel flow is to treat the inflow and outflow boundaries accurately. The inflow boundary was modeled by generating three layers of moving ghost particles ahead of the physical upstream boundary. On the other hand, when a fluid or sediment particle moves outside the physical downstream boundary, it becomes a ghost boundary particle and retains the velocity before it moves more than $2 h$ from the downstream outlet. The purpose of this treatment is to avoid the generation of spurious pressure waves caused by the direct creation or deletion of fluid particles (Federico et al. 2012). The moving velocity of the inflow particles is determined by dividing the inflow discharge per unit width (2D simulation) by the water depth. The sediment particles enter the computational domain together with the fluid, the amount of which is computed by the sediment supply rate.

\section{SPH Sediment Model}

\subsection{Fluid-sediment interaction strategy}

One of the objectives of this study is to investigate the effect of strong sediment transport on the formation and development of the dynamic hydraulic jump in an open channel. To simulate the interaction between flow motion and sediment transport, a new fluid-sediment interaction model is proposed here. Considering that the motion of the sediment relates to that of the water flow, the velocity of the sediment particles can be interpolated by the surrounding fluid particles and the physical phenomenon (i.e. the sediment motion slightly lags behind the flow) is addressed by multiplying with the correction coefficient. The deposition and incipient motion of sediment particles affect the ascent and descent of the riverbed (i.e. the riverbed evolution), thus affecting the motion of the water flow instead. This fluid-sediment interaction model will be elaborated in more details in the following sections.

\subsection{Sediment motion}

\subsubsection{The motion velocity of a sediment particle}

The motion of sediment particle is affected by the gravity and the water flow. A sediment particle falls in water under the influence of gravity. The settling velocity $\omega$ in the vertical direction is computed 
by using an empirical formula that was derived in Wuhan University of Hydraulic and Electrical Engineering (Zhang 1961) as follows:

$$
\omega=-13.95 \frac{v_{0}}{D}+\sqrt{\left(13.95 \times \frac{v_{0}}{D}\right)^{2}+1.09 \frac{\rho_{s}-\rho}{\rho} g D}
$$

where $D=$ diameter of sediment grains (typically used as the surface median size for heterogeneous bed particles); and $\rho_{s}=$ density of the sediment grains.

Sharmov and Levy assumed that the average velocity of the bed-load motion is proportional to the difference between the velocity acting on the bed particle and the velocity for the initiation motion of a particle on the bed (Chien and Wan 1999). Therefore, it is possible to estimate the velocity of sediment particles by interpolating the velocity of fluid particles in the support domain of the sediment particles (which is also $2 h$, being consistent with that of the fluid particles). Further, taking account of the fact that the sediment bed-load motion lags behind the water flow, a reduction coefficient $\beta$ is considered as the proportional coefficient. According to statistical analysis, $\beta=0.8$ could lead to the most continuous distribution of the sediment particles in the flow. Hence, the movement velocity of the sediment particles can be calculated from the SPH interpolation equation as below:

$$
\mathbf{u}_{b}=\frac{\sum_{a} \frac{m_{a}}{\rho_{a}} \times W_{a b} \times \mathbf{u}_{a}}{\sum_{a} \frac{m_{a}}{\rho_{a}} \times W_{a b}} \times \beta
$$

where $b=$ sediment particle; $\rho_{a}=1000 \mathrm{~kg} / \mathrm{m}^{3} ;$ and $a=$ fluid particle that affects the motion of the sediment particle. By further considering the gravity, the vertical velocity of a sediment particle is the superposition of the components from Equation (8) and (9); and the horizontal velocity of the sediment contains only the component from Equation (9).

\subsubsection{The incipient velocity of a single sediment particle}

Because the incipient motion of the sediment is a stochastic matter, a statistically-averaged assumption ignoring the random distributions should be made when dealing with this problem. To assess whether a single sediment particle is movable or stationary, the critical incipient velocity $u_{c}$ can be computed by the Sharmov formula as follows:

$$
u_{c}=1.14 \sqrt{\frac{\gamma_{s}-\gamma}{\gamma} g D}\left(\frac{H}{D}\right)^{1 / 6}
$$

where $H$ = flow depth; $\gamma=$ specific weight of fluid; and $\gamma_{s}=$ specific weight of sediment grains. When the resultant velocity of the sediment particles calculated in Section 2.2.1 is larger than the critical incipient velocity, the sediment particles will move; otherwise, they remain stationary.

\subsection{Evolution of riverbed}

The fluid particle (the blue dot in Figure 2(a)) motions induce the sediment (the yellow square in Figure 2(a)) transport that consequently causes the riverbed evolvement, as shown in Figure 2. Two types of boundary particles are defined to represent the morphology change of the riverbed, also shown in Figure 2. Initially, boundary particle 2 (the red dot in Figure 2(a)) is generated, overlapping with the fixed wall particles. If the sediments deposit in (siltation) or leave from (erosion) the support domain of boundary particle 2, this particle then moves up or down vertically. If no sediment is involved within this area, the boundary particle 2 remains stationary as shown in Figure 2(a). The boundary particles 1 and 2 act as the boundary particles to the fluid flow. Hence, their density is equal to the water density but not the density of the sediment particles. The mass of boundary particle 2 is updated by $\frac{h_{b p 2}}{l_{0}} \times\left(\rho \times l_{0}^{2}\right)$, in which $h_{b p 2}$ is the rising height of the boundary particle 2, relative to its nearest boundary particle 1 (which will be introduced later) in the vertical line or to its corresponding fixed wall particle if such a boundary particle 1 has not been added. Hence, the mass of boundary particle 2 in Figure 2(a) should be zero because it coincides with the fixed wall particle. If the boundary particle 2 moves up by a distance of $l_{o}$, the boundary particle 1 (the gray dot in Figure 2(b)) is generated on the corresponding position of particle 2. Then the mass of boundary particle 1 is simply updated by $m=\rho \times l_{0}^{2}$, and the mass of boundary particle 2 becomes zero. During the calculation process, boundary 
particles 1 and 2 are treated as solid wall particles, and therefore, they also influence the motion of the fluid particles.

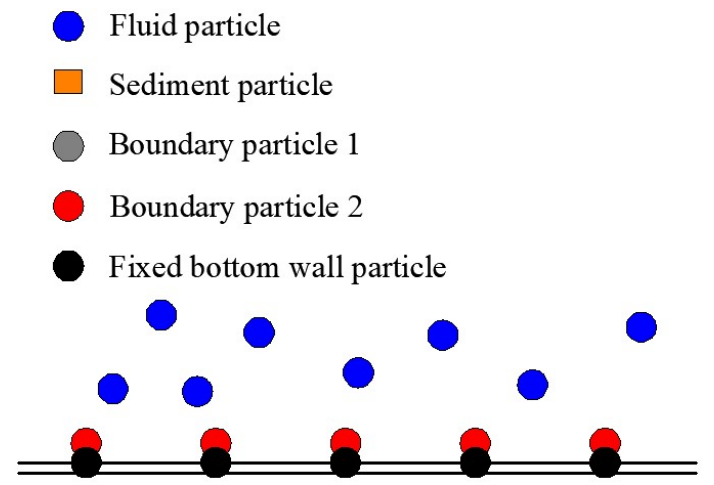

(a)

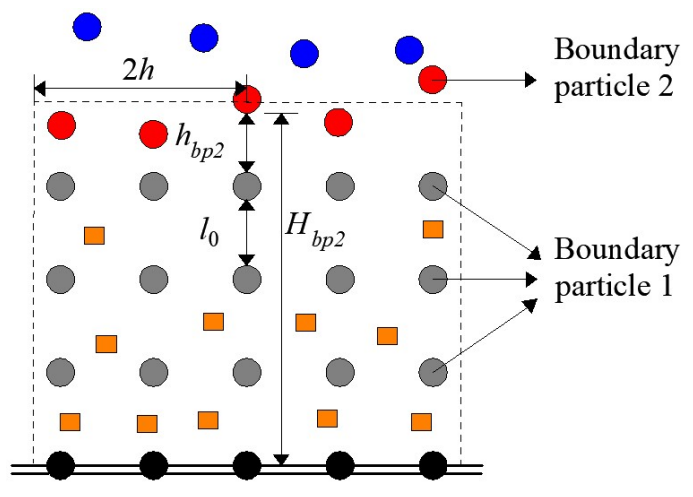

(b)

Figure 2 Five different types of particles near the boundary of riverbed: (a) without sediment influence; and (b) with sediment influence

One important parameter to determine is the increasing height of the boundary particle 2 relative to the original riverbed. According to the sediment mechanics, this should be dependent on the number of nearby sediment particles. Specifically, with more neighboring sediment particles, the height increase will be larger; and vice versa. In this study, the sediment particles (whose number is denoted by $n_{s p}$ ) that affect the increasing height of a boundary particle 2 is bounded in the region delineated by the horizontal line through the target boundary particle 2, the original riverbed, and two vertical lines of horizontal distance $2 h$ to the target boundary particle 2 , i.e. the dash-line enclosed region in Figure 2 (b). The contribution to the increasing height $\alpha$ from one sediment particle is evaluated as follows:

$$
n_{1} \times \alpha \times A_{d}=V_{d} \times n_{2} \times \frac{(1-p)}{(1-\lambda)}
$$

This relates the sediment volume conservation between the numerical model $\left(n_{1}\right)$ and the real situation $\left(n_{2}\right)$, where $p=$ probability of the riverbed sediment being transferred into the bed-load. Thus, the probability of the bed-load participating in the riverbed evolution (namely, affecting the elevation of the boundary particle 2) is (1-p). $A_{d}=$ bottom rectangular area represented by a marker sediment particle; and $\lambda=$ porosity of the sediment bed, for most 2-mm sediment grains being $50 \%$ according to field observations. The sediment grain volume is calculated by $V_{d}=\frac{4}{3} \pi\left(\frac{D}{2}\right)^{3} . \alpha$ can be calculated by Equation (11) and reflects the sediment particle properties and flow intensity. After the parameters $n_{s p}$ and $\alpha$ are determined, the total rising height of the boundary particle 2 is determined as $H_{b p 2}=n_{s p} \times \alpha$. Then $h_{b p 2}$ is computed as $h_{b p 2}=H_{b p 2}-l_{0} \times n_{b p 1}$, where $n_{b p 1}$ is the number of related boundary particle 1 in the vertical line.

\section{Model validation - dam break flow over a movable sediment bed}

The developed SPH fluid-sediment interaction model is validated by the experimental case of movable bed erosion induced by dam break flows (Spinewine 2005). The numerical flume is $6 \mathrm{~m}$ long with an initial water column of $3 \mathrm{~m}$ long and $0.35 \mathrm{~m}$ deep. The thickness of the sediment layer is set to be $0.1 \mathrm{~m}$, which ensures that there are enough sediments for erosion while not introducing superfluous sediment particles. The initial particle spacing of sediment particles is selected to be $0.01 \mathrm{~m}$. The predicted free surface and bed evolution profiles at two time instants are compared with the experimental results of Spinewine (2005) in Figure 3.

The computed free surface profiles match the experimental data generally well although the relatively large discrepancies appear at local area of $0.2 \mathrm{~m}-0.4 \mathrm{~m}(t=0.25 \mathrm{~s})$ and $0.6 \mathrm{~m}-0.8 \mathrm{~m}(t=$ $0.75 \mathrm{~s}$ ). As for the sediment bed profiles, the numerical model predicts the sediment scour length well although the scour depth shows relatively large errors. This shows that the present numerical model can simulate the bed erosion induced by rapid flows with a satisfactory accuracy. 

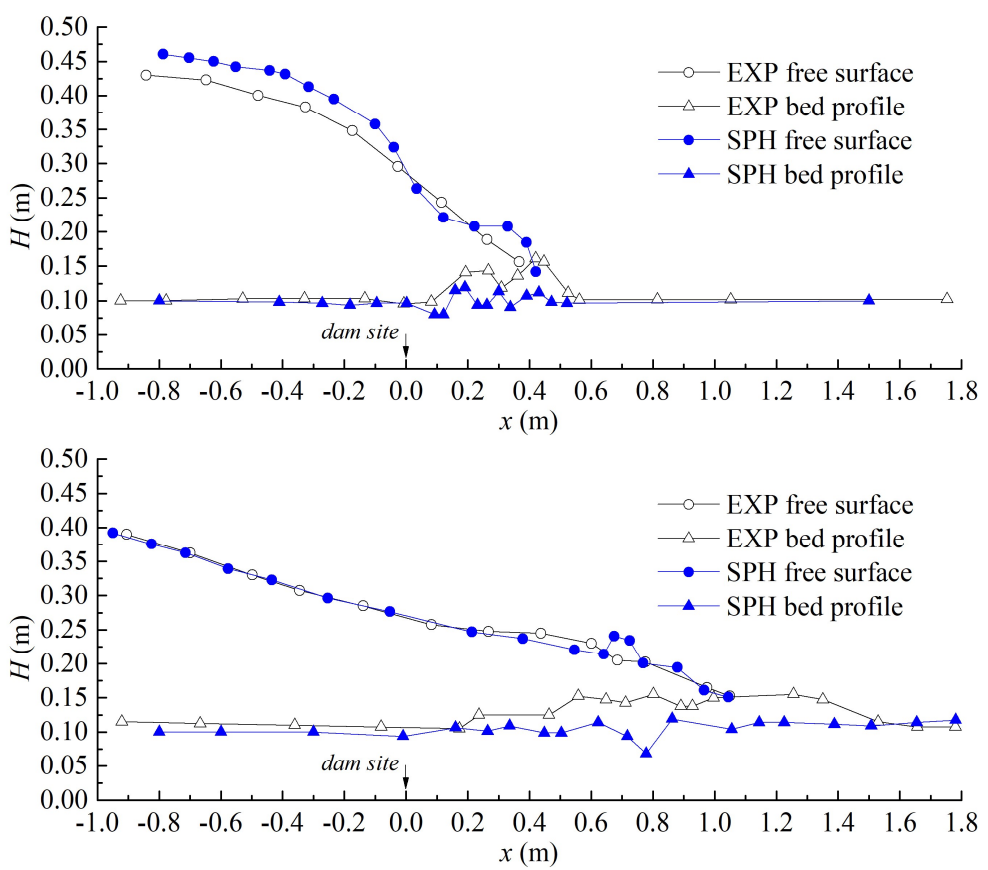

Figure 3 Free surface and bed profiles at $t=0.25 \mathrm{~s}$ (top figure) and $0.75 \mathrm{~s}$ (bottom figure): comparison between SPH simulation and experimental data in Spinewine (2005)

Based on this case, the convergence of the developed model with initial particle spacing is evaluated. Three particle sizes, i.e. $l_{o}=0.002 \mathrm{~m}, 0.005 \mathrm{~m}$ and $0.01 \mathrm{~m}$ are studied. The predicted free surface and bed profiles at $t=0.25 \mathrm{~s}$ with different particle spacing are presented in Figure 4. In general, the results of $l_{o}=0.005 \mathrm{~m}$ and $l_{o}=0.002 \mathrm{~m}$ are close, while those of $l_{o}=0.01 \mathrm{~m}$ show some discrepancies especially near the wave front. This shows the convergence of the model. The initial particle spacing of $0.002 \mathrm{~m}$ is used in the following computations. A simulation of a physical time of $40 \mathrm{~s}$ takes around 10 hours on a personal computer equipped with Intel (R) Core (TM) i5 - 7200U CPU @ 2.50 GHz.

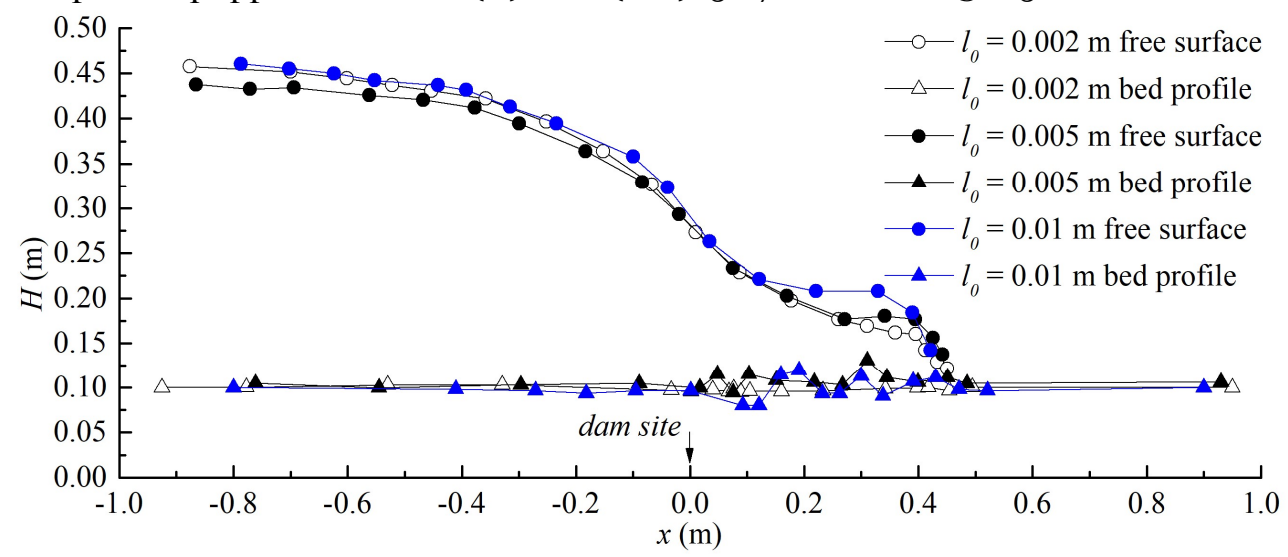

Figure 4 Free surface and bed profiles at $t=0.25 \mathrm{~s}$ : comparison between different initial particle space

\section{Numerical and Experimental Study}

\subsection{Experimental setup and phenomena}

Experimental studies were conducted in the glass flume of the State Key Laboratory of Hydraulics and Mountain River Engineering at Sichuan University, China. The upper reach of the flume is $3.2 \mathrm{~m}$ long, the lower reach is $4.4 \mathrm{~m}$ long, and the flume is $0.2 \mathrm{~m}$ wide and $0.3 \mathrm{~m}$ deep. The slope of the flume can be adjusted within the range of $1 \%-7 \%$ to simulate the steep upstream and gentle downstream mountainous rivers (Figure 5). In the early stage of each test case, the water level and flow state without sediment were recorded. After the water flow became stable, the sediments were gradually added at the flume inlet. The adjustment range of the feeding machine was $0-0.45 \mathrm{~kg} / \mathrm{s}$, which can satisfy the requirement of sufficient sediment supply. The experimental sediment grain diameter was $2 \mathrm{~mm}$ and the density of the sediment was $2650 \mathrm{~kg} / \mathrm{m}^{3}$ regardless of the influence of size distributions. In the experiment, the developments of dynamic hydraulic jump and riverbed siltation were also recorded by a camera placed on the track in front of the flume. In the prototype case as shown in Figure 1, the slopes of the upstream and downstream reaches are $6.0 \%$ and $1.2 \%$, respectively, for the left erosion ditch. 
Therefore, these were set to $J_{1}=5.0 \%$ and $J_{2}=1.0 \%$ in the experimental flume to study the physical problem similar to the real situation. The inflow discharge and sediment intensity are the two important parameters. Six experimental cases described in Table 1 were tested. By using one of the cases, i.e. per unit flow discharge $q=0.016 \mathrm{~m}^{3} /(\mathrm{s} \cdot \mathrm{m})$ and per unit sediment intensity $q_{s}=0.986 \mathrm{~kg} /(\mathrm{s} \cdot \mathrm{m})$, this section elaborates the phenomena and mechanism of the initiation and development of the dynamic hydraulic jump.

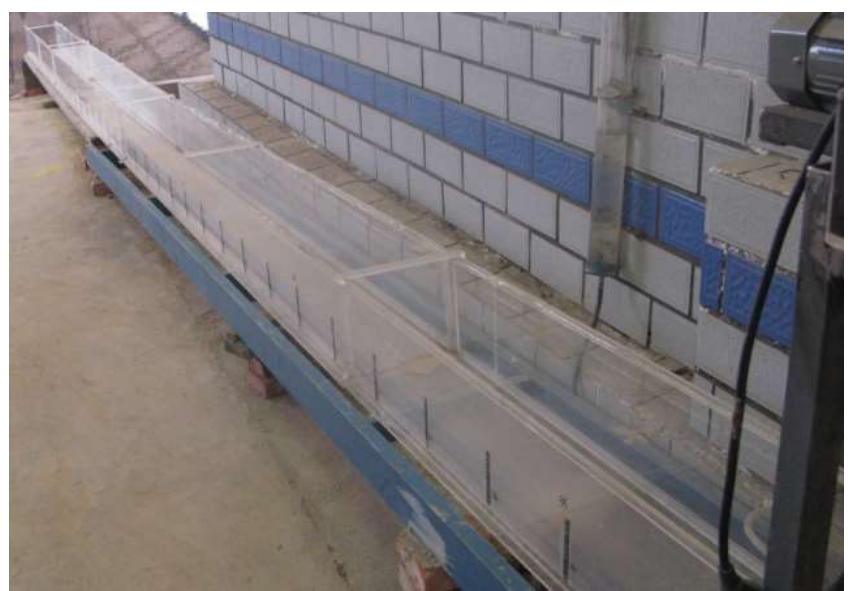

Figure 5 Experimental sediment flume with varying bed slopes of upstream and downstream

Without the influence of sediment, the upstream and downstream flows are both uniform, and the water level change appears only near the slope change point (Figure 6(a)). Since the Fr number of the channel flow computed as $F r=v / \sqrt{g H}$ is larger than 1.0 and hence the flow is in the supercritical regime. Thus, the influence of backwater is not substantial, even though the water level over the downstream slope is higher than that over the upstream one. On the other hand, when the flow with saturated sediment contents from the upstream $5 \%$ steep slope enters the downstream $1 \%$ mild one, the flow velocity decreases gradually owing to the consumption of the flow energy, and the sediment transport capacity of the flow is reduced as well. When the sediment transport capacity is below the sediment intensity, the sediments first deposit over the $1 \%$ slope and the flow retardation due to the sediment deposition increases. Meanwhile, the siltation further leads to an increase in the riverbed, thereby, rendering a gentle local slope. The superposition of the two factors further reduces the flow energy at the siltation position, resulting in more sediment to be silted (see Figure 6(b)). When the siltation develops to a certain extent, it further renders a gentler local slope at the siltation position (equivalent to the elevation of the erosional basis) and changes the supercritical flow state of the local river reach into the subcritical flow. As a result, a hydraulic jump occurs at the interface of the supercritical and subcritical flows, which increases the water level significantly (Figure 6(c)). After the hydraulic jump forms, a large amount of sediment siltation appears at the front of the original siltation position, and the sediment develops upstream rapidly in the form of a retrograde sand wave.

During the development of the retrograde sedimentation, the water depth increases significantly along the flume. The most significant change in the water depth during the siltation process occurs at the siltation front. The increase in water depth is affected primarily by the riverbed elevation owing to the siltation and hydraulic jump at the local interface of the supercritical and subcritical flows (see Figure 6(d)). The relative decrease in the local flow energy is the premise of the rapid siltation on the riverbed, and the siltation front is the basis for subsequent retrograde development. After the siltation front has passed through, the water level increases as the siltation causes the riverbed to ascend. This phenomenon is shown in Figure 6(e). The siltation thickness can reach or exceed the clear water depth. If considering the multiple effects of hydraulic jump, sediment flux and flow resistance, the water depth at the siltation front can reach three times higher than the clear water depth. When the retrograde sand waves propagate to the flume inlet, the whole riverbed is silted. Further, the water level is much higher than the situation with no sediment because of the siltation of the riverbed, the increase in the water depth behind the hydraulic jump, and the increase in the riverbed resistance.

In the previous studies of flood disaster in mountainous areas, researchers usually ignored the sediment effect. In this work, it is found that when the sediment supply intensity is high, the siltation affects the riverbed evolution and causes more severe flood disasters. Hence, it is crucial to consider the effect of sediment transportation (particularly when the sediment intensity is high) in the assessment of mountainous river hazards. 
Table 1 Summary of experimental and numerical test conditions

\begin{tabular}{|c|c|c|c|c|c|}
\hline \multirow{2}{*}{ Case number } & & \multicolumn{2}{|c|}{ Bed slope } & \multirow{2}{*}{$q\left(m^{3} / s \cdot m\right)$} & \multirow{2}{*}{$q_{s}(\mathrm{~kg} / \mathrm{s} \cdot \mathrm{m})$} \\
\hline & & Upstream & Downstream & & \\
\hline 1 & \multirow{6}{*}{$\begin{array}{l}\text { Experimental } \\
\text { case }\end{array}$} & \multirow{6}{*}{$5 \%$} & \multirow{6}{*}{$1 \%$} & 0.016 & 0.636 \\
\hline 2 & & & & 0.016 & 0.848 \\
\hline 3 & & & & 0.016 & 0.986 \\
\hline 4 & & & & 0.024 & 0.636 \\
\hline 5 & & & & 0.024 & 0.848 \\
\hline 6 & & & & 0.024 & 0.986 \\
\hline 7 & \multirow{35}{*}{$\begin{array}{c}\text { Numerical } \\
\text { case }\end{array}$} & \multirow{20}{*}{$5 \%$} & \multirow{20}{*}{$1 \%$} & 0.008 & 0.636 \\
\hline 8 & & & & 0.008 & 0.763 \\
\hline 9 & & & & 0.008 & 0.848 \\
\hline 10 & & & & 0.008 & 0.986 \\
\hline 11 & & & & 0.016 & 0.580 \\
\hline 12 & & & & 0.016 & 0.636 \\
\hline 13 & & & & 0.016 & 0.763 \\
\hline 14 & & & & 0.016 & 0.848 \\
\hline 15 & & & & 0.016 & 0.986 \\
\hline 16 & & & & 0.016 & 1.060 \\
\hline 17 & & & & 0.016 & 1.220 \\
\hline 18 & & & & 0.016 & 1.250 \\
\hline 19 & & & & 0.016 & 1.330 \\
\hline 20 & & & & 0.024 & 0.636 \\
\hline 21 & & & & 0.024 & 0.763 \\
\hline 22 & & & & 0.024 & 0.848 \\
\hline 23 & & & & 0.024 & 0.986 \\
\hline 24 & & & & 0.024 & 1.170 \\
\hline 25 & & & & 0.024 & 1.220 \\
\hline 26 & & & & 0.024 & 1.290 \\
\hline 27 & & \multirow{5}{*}{$5 \%$} & \multirow{5}{*}{$2 \%$} & 0.016 & 0.700 \\
\hline 28 & & & & 0.016 & 0.800 \\
\hline 29 & & & & 0.016 & 0.850 \\
\hline 30 & & & & 0.016 & 1.200 \\
\hline 31 & & & & 0.016 & 1.330 \\
\hline 32 & & \multirow{5}{*}{$4 \%$} & \multirow{5}{*}{$2 \%$} & 0.016 & 0.600 \\
\hline 33 & & & & 0.016 & 0.800 \\
\hline 34 & & & & 0.016 & 0.830 \\
\hline 35 & & & & 0.016 & 1.100 \\
\hline 36 & & & & 0.016 & 1.280 \\
\hline 37 & & \multirow{5}{*}{$3 \%$} & \multirow{5}{*}{$2 \%$} & 0.016 & 0.500 \\
\hline 38 & & & & 0.016 & 0.600 \\
\hline 39 & & & & 0.016 & 0.800 \\
\hline 40 & & & & 0.016 & 0.900 \\
\hline 41 & & & & 0.016 & 1.000 \\
\hline
\end{tabular}

\subsection{SPH simulation results}

To further explore the mechanisms of the dynamic hydraulic jump, the case presented in Section 4.1 is simulated by the developed SPH fluid-sediment interaction model. To reproduce the motion of a single sediment particle and the detailed flow structure, an initial particle spacing of $0.002 \mathrm{~m}$ was selected. A fixed time step of $0.0005 \mathrm{~s}$ was adopted to satisfy the Courant-Friedrichs-Lewy condition, i.e. $\Delta t=0.4 \times \min \left[h / \max \left(\sqrt{g \times H_{i}},\left\|\mathbf{u}_{i}\right\|\right)\right]$.

Figure 7 shows the predicted water surface profiles and the sediment distributions by SPH throughout the entire process of dynamic hydraulic jump and sediment evolutions. Figure 8 shows the numerical results at two enlarged sections of flow and sediment, compared with the experimental photos. In the upstream reach, the sediment transport capacity is consistent with the sediment supply intensity so as to reach the equilibrium. In the downstream reach, on the other hand, the flow energy decreases and the sediment transport capacity reduces, the sediment quickly drops and forms a siltation dam on the riverbed. At the initial siltation stage, the thickness of the deposits is small. When the 
upstream flow passes through the siltation front, the siltation dam produces the "trajectory bucket" effect. The influence is that the real water depth at the siltation position is much higher than the normal upstream depth, but the flow direction is still towards the downstream (Figure 7(b); Figure 8(a)). At the location of the siltation dam, the local kinetic energy is converted into potential energy, which contributes to the increase in the water depth. The energy conversion further leads to the loss of more flow kinetic energy near the siltation position. The local sediment transport capacity is further reduced and more upstream sediments are deposited. In addition, the water flow at the siltation front rotates owing to the hydraulic jump, producing a flow velocity direction pointing upstream, causing the sediment particles to settle at the siltation front (Figure 8(b)). The sediment particles can even be pushed back upstream by the swirling flow. The sediment transport capacity at the siltation front is less than the upstream sediment supply intensity all the time, thereby, causing more sediment to be deposited in the channel. Further, the siltation front continues to develop upstream, thus resulting in a retrograde sedimentation process. As shown, the SPH model can capture most of the key physical phenomena including the initiation/development of the sedimentation and the dynamic hydraulic jump. This shows the acceptable accuracy of the developed SPH fluid-sediment interaction model. The computed velocity field in Figure 8 is another important supplement of the experimental results to study the detailed physics of the retrograde development of the hydraulic jump.
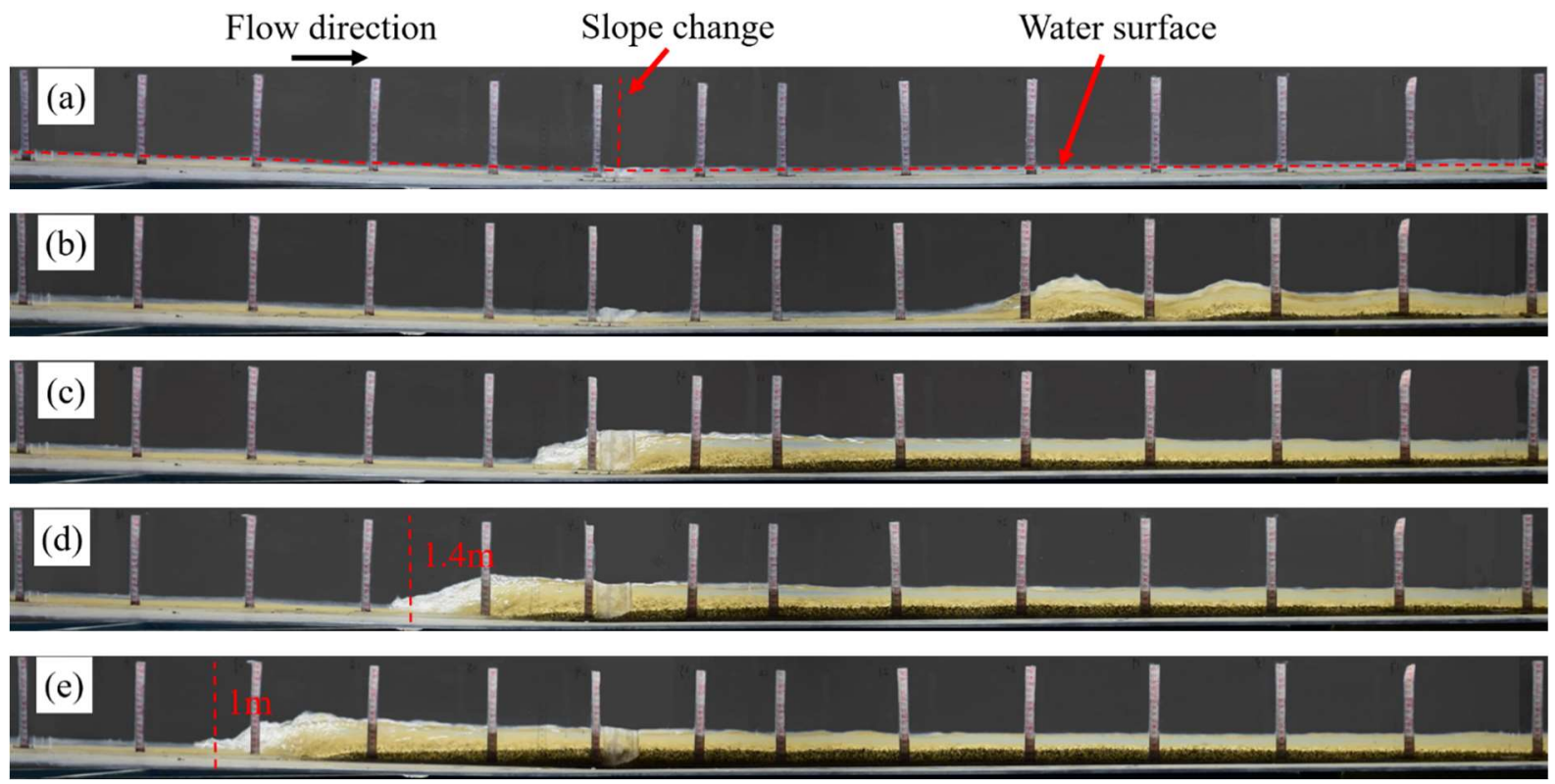

Figure 6 Dynamic hydraulic jump in experiment: (a) without sediment; (b) initial stage of hydraulic jump; and (c)

- (e) dynamic hydraulic jump propagates upstream, until 1.4-1.0 $\mathrm{m}$ from the inflow boundary
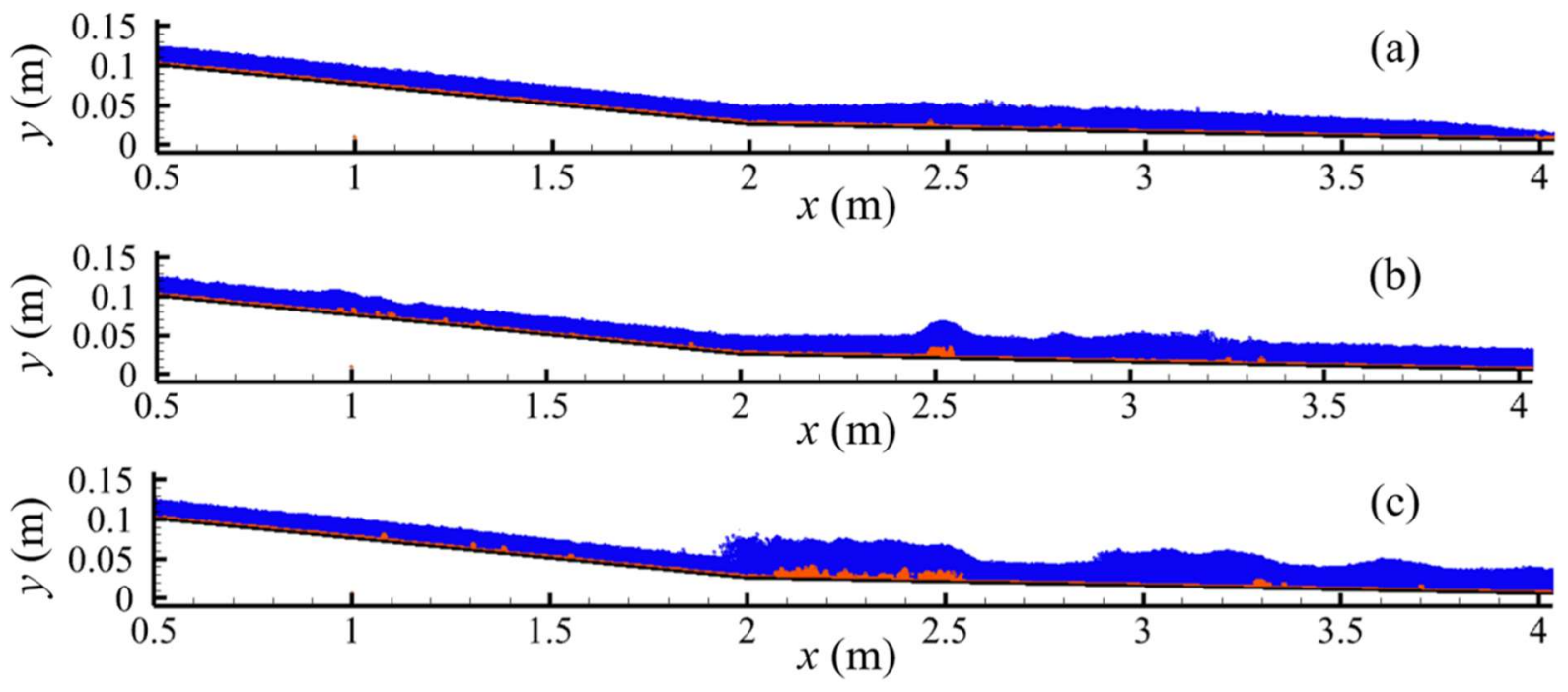

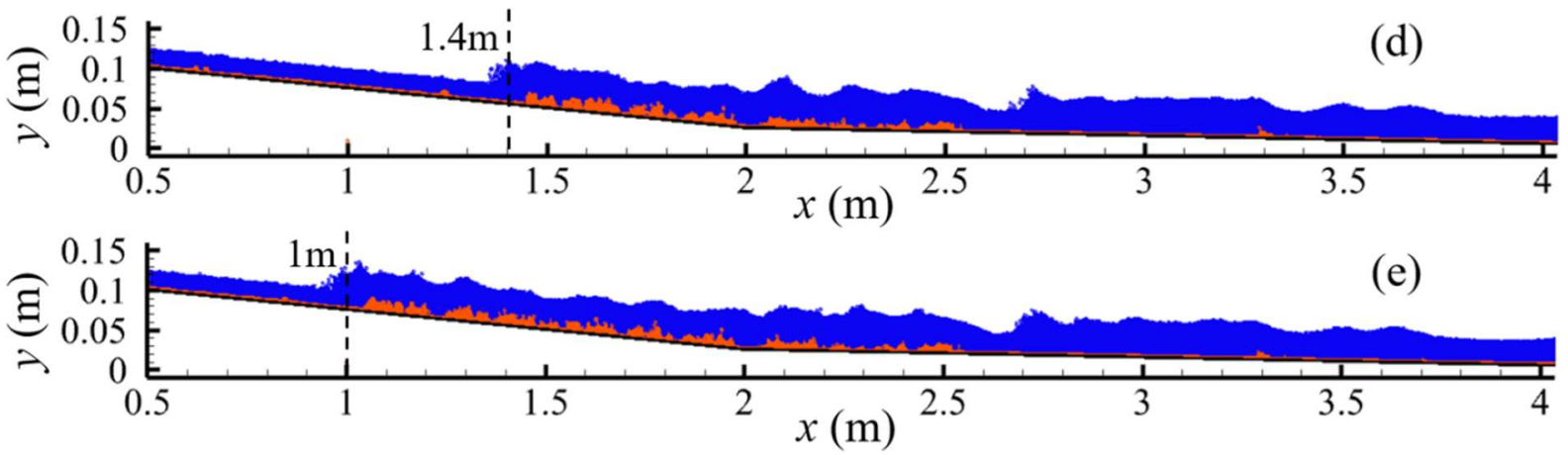

Figure 7 Dynamic hydraulic jump in SPH: (a) without sediment; (b) initial stage of hydraulic jump; and (c) - (e) dynamic hydraulic jump propagates upstream, until 1.4-1.0 $\mathrm{m}$ from the inflow boundary
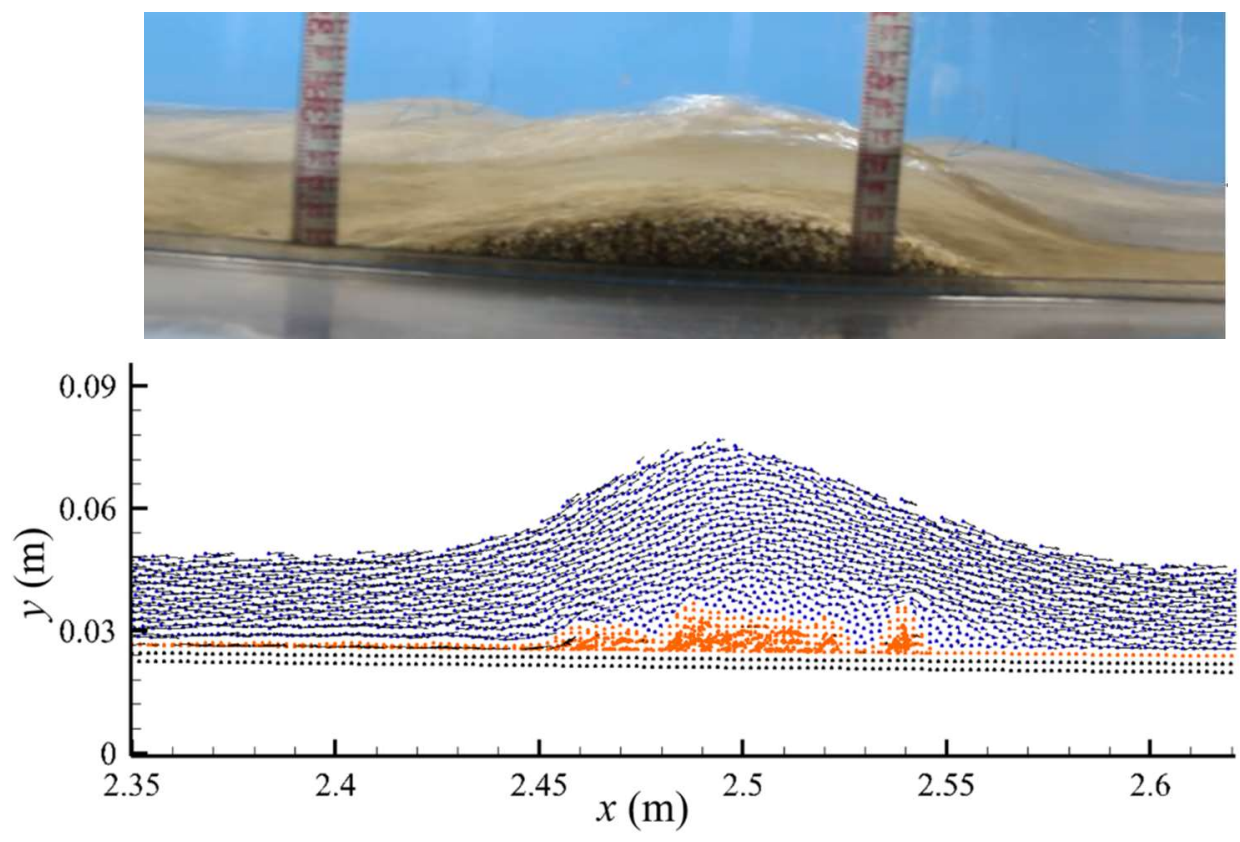

(a)
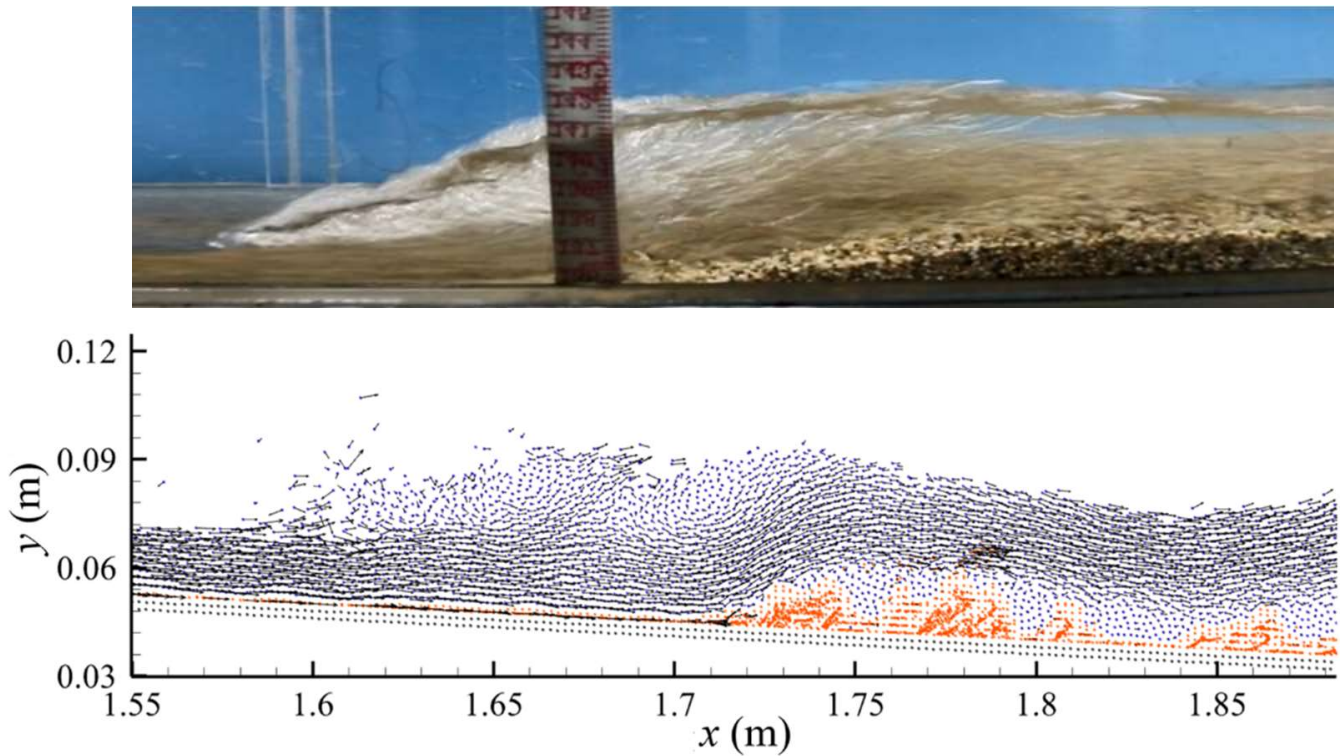

(b)

Figure 8 Enlarged sections of flow and sediment, comparing experimental and SPH results: (a) location of sedimentation initiation; and (b) location of dynamic hydraulic jump wave front (where retrograde sedimentation develops) 


\subsection{Discussion of the results}

By studying on the experimental and numerical results, it is discovered for the first time that under the strong sediment transport, the sedimentation may cause dynamic hydraulic jump and further lead to the retrograde propagation of the sediment, causing water level to surge over the steep slopes. When a low flow discharge occurs but with a large amount of sediments in field, the water level may far exceed that of the clear water with the same discharge. Finally, even if the flood discharge does not exceed the flood control standard, the water level could be abnormally high and exceed the embankments, making it difficult for the flood control practice to work in the mountainous rivers. The following sections discuss on the critical triggering conditions, propagation characteristics, and the initial siltation location of the retrograde sedimentation over steep slopes.

\subsubsection{Critical triggering conditions of retrograde sedimentation}

Owing to the lack of a formula for calculating the bed-load transport over steep slopes, it is considered to transform the Meyer-Peter formula into formulas using the bed-load transport intensity parameter and the flow intensity parameter. In a high-intensity bed-load motion, the Meyer-Peter formula is transformed into the following (Chien and Wan 1999):

$$
\Phi=8 \Theta^{3 / 2}
$$

where $\Phi=\frac{\mathrm{g}_{b}}{\gamma_{s}}\left(\frac{\gamma}{\gamma_{s}-\gamma}\right)^{1 / 2}\left(\frac{1}{g D^{3}}\right)^{1 / 2}$; and $\Theta=\frac{\gamma H J}{\left(\gamma_{s}-\gamma\right) D}$, where $\mathrm{g}_{\mathrm{b}}=$ bed-load transport rate per unit width and $J=$ slope.

The sediment transport capacity per unit width under different inflow discharges can be calculated from Equation (12). For example, if the inflow discharge is $0.016 \mathrm{~m}^{3} /(\mathrm{s} \cdot \mathrm{m})$, the maximum sediment transport capacities in the $5 \%$ upstream channel and $1 \%$ downstream channel are calculated to be 1.25 and $0.16 \mathrm{~kg} /(\mathrm{s} \cdot \mathrm{m})$, respectively. The sediment supply intensity described in Section 4.1 lies somewhere between these two, and so the retrograde sedimentation is initiated. To verify the triggering conditions of this, five additional experimental tests were performed by changing the inflow discharge and the sediment supply intensity. The test parameters are also listed in Table 1, from which retrograde sedimentations were reproduced in all the experiments.

It can be found that when the sediment supply intensity lies between the sediment transport capacity of the upstream and downstream channels, retrograde sedimentation may appear in the downstream near the slope change point. This should not occur if the sediment supply intensity is slightly larger than the sediment transport capacity of the downstream channel, under which condition the sediments can still be transported a certain distance and eventually move to the end of the flume due to the inertia effect. That is to say, to trigger the retrograde sedimentation in a water-sediment flow, the sediment transport capacity of the downstream channel must be reduced significantly. In other words, in the initial siltation stage, the triggering of retrograde sedimentation requires the sufficient sediment siltation per unit time at the position of the siltation dam, which can cause the flow kinematic energy to convert into the potential energy. This requires that the upstream sediment supply intensity should be significantly higher than the sediment transport capacity of the downstream flow.

It has been found that the critical triggering condition of the retrograde sedimentation are related to the upstream-downstream slope ratio (reflecting inertia) and the upstream sediment supply intensity (reflecting the amount of sediment that can be deposited per unit time in the downstream channel). To reveal the detailed mechanisms, a more comprehensive parametric study was conducted using the developed SPH model by changing the flume slope and the sediment supply intensity, also shown in Table 1. In the laboratory experiment, the upstream-downstream slope ratio of the flume is $J_{1} / J_{2}=5$, therefore, the mathematical model reduced the ratio to yield the critical ratio. The downstream bed slope of $2 \%$ is fixed, and the upstream one is changed to $5 \%, 4 \%$, and $3 \%$. Meanwhile, the sediment supply intensity range is also expanded to obtain the critical value. All of the parameters of the test cases are listed in Table 1 and the calculation results are shown in Figure 9, where $g_{b 2}^{*}=$ the maximum sediment transport capacity in the downstream channel. It is shown that if the upstream and downstream slopes are $3 \%$ and $2 \%$, respectively, changing the sediment supply intensity cannot trigger the retrograde sedimentation. When the upstream bed slope is twice the downstream slope and the upstream sediment supply intensity is around 2 times larger than the maximum downstream sediment transport capacity, the retrograde sedimentation occurs and therefore, triggers the retrograde propagation of the dynamic hydraulic jump as well. 


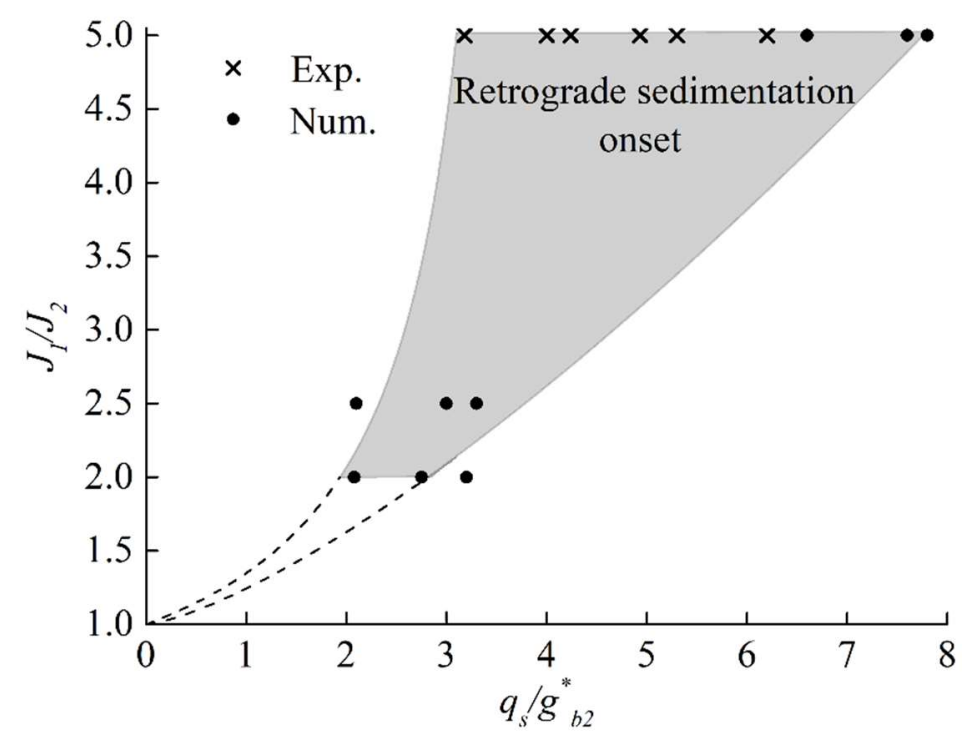

Figure 9 Critical triggering conditions of the retrograde sedimentation onset

\subsubsection{Retrograde propagation of the siltation front}

During the retrograde development of the siltation front, the surge in the water level may cause the floods to exceed the embankments. Further, the hydraulic jump accompanying the siltation front may also impact and erode the embankments. Meanwhile, once the retrograde sedimentation starts, the downstream sedimentation reaches always remain at the high water level for a long time, and the flood transit times increase as well. Therefore, it is necessary to study the development law of the siltation front to better understand this physical process.

The propagation velocity of the siltation front is affected by the riverbed topography. This phenomenon is studied based on the developed SPH model by dividing the wave flume into several segments of horizontal equidistance. The mean propagation velocity $\bar{v}$ of the retrograde sediment front in each section is pointed at the middle of that section. Figure 10 shows the results of the model, where $d$ is the distance from the flume inlet. As can be seen, the retrograde propagation velocity in the steeper flume section is significantly slower than that in the milder section. This is primarily affected by the flow dynamic conditions. The steeper the slope is, the higher is the flow velocity and the larger is the sediment transport capacity, which is not conducive to the sedimentation. So, the retrograde development velocity is slower. Figure 10 also illustrates that the retrograde velocity is related to the sediment supply intensity. If more sediment is supplied, the sediment concentration of the flow becomes higher and the flow resistance becomes larger under the same flow discharge condition. More sediment could be dropped at the siltation front per unit time when the flow pattern changes. As a result, the retrograde development velocity of the sedimentation becomes higher.

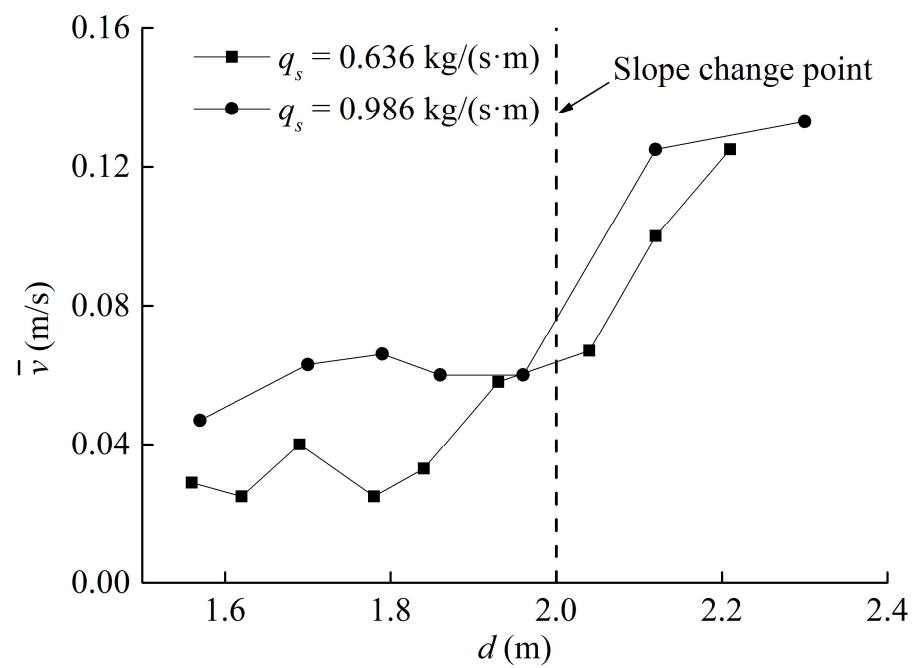

Figure 10 Propagation velocity of dynamic hydraulic jump for different sediment supply intensities under flow discharge $q=0.016 \mathrm{~m}^{3} /(\mathrm{s} \cdot \mathrm{m})$ 
Based on the numerical model, the effect of flow discharge on the retrograde development of the sedimentation is studied with the results shown in Figure 11. Under the same condition of sediment supply intensity, the larger the flow discharge is, the slower is the retrograde development velocity of the dynamic jump. This is attributed to the following two reasons: (1) The sediment transport capacity is proportional to the higher power of the flow discharge. The larger the discharge is, the higher is the sediment transport capacity of the flow; and (2) The larger the discharge is, the lower is the sediment concentration of the flow. In summary, if the inflow discharge becomes larger, less sediment materials could deposit at the siltation front per unit time, thus, limiting the retrograde development velocity.

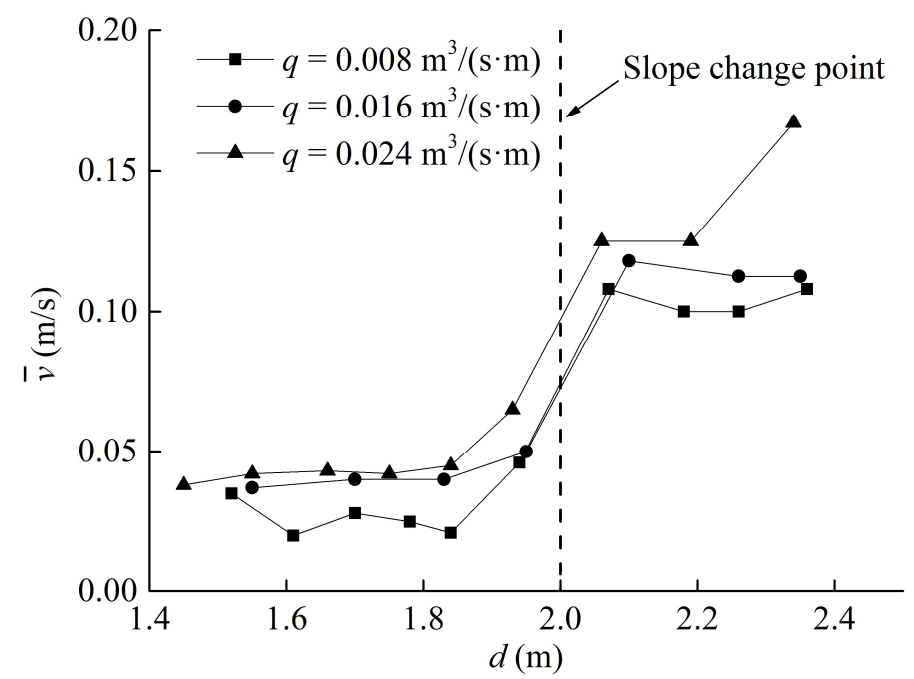

Figure 11 Propagation velocity of dynamic hydraulic jump for different inflow discharges under sediment supply intensity $q_{s}=0.763 \mathrm{~kg} /(\mathrm{s} \cdot \mathrm{m})$

\subsubsection{Initial siltation position}

To control the disastrous effect of the sediment, the determination of the initial siltation position is particularly important for the construction of protection works. To study the effect of sediment intensity and inflow discharge on the initial siltation positions, the results under different inflow discharges and sediment intensities are summarized in Figure 12. In some cases, the initial siltation does not happen at a concrete position but occurs simultaneously within a range. For these, the upstream siltation point is used as the initial siltation position.

As shown in Figure 12, the higher the sediment supply intensity and the concentration of the flow are, the closer is the initial siltation position to the upper reach of $1 \%$ slope under the same discharge condition. If the flow discharge becomes larger, the initial siltation position is farther away from the upper reach of $1 \%$ slope under the same sediment intensity condition. One explanation is that when the strong sediment transport flow enters the gentler slope, the flow velocity reduces, thus, causing a decline in the sediment transport capacity and creating the condition of sedimentation owing to the adjustment of the slope and the flow resistance effect (due to the velocity difference between the sediment and water flow). The higher the sediment intensity is, the larger is the resistance of the water flow. Finally, the sediment concentration becomes supersaturated in a short distance. As a result, the initial siltation position is closer to the upper reaches. When the sediment intensity remains constant, the larger the flow discharge is, the lower is the sediment concentration of the mixture flow and the larger is the sediment transport capacity, so the flows can carry the sediment for a much longer distance before its sedimentation; therefore, the initial siltation position is closer to the lower reaches, in which situation it could lead to a wider range of flood disasters.

Another possible explanation is that the flume is composed of two different slopes. When the flow enters the gentler slope, a transitional state occurs owing to the flow inertia effect, namely, a transitional section appears near the slope change point. When the flow discharge is low, once it enters the transitional section, the flow velocity decreases rapidly and the sediment transport capacity reduces within a short distance. Subsequently, the supersaturated state of the sediment caused by the decrease in the flow velocity occurs, and the initial siltation position is closer to the upper reaches. On the other hand, if the inflow discharge increases, the inertia of the flow entering the gentler slope is larger and the sediment transport capacity can be maintained for a longer time. Therefore, the initial siltation position is farther away from the upper reaches. In general, the determination of the initial siltation position is useful for predicting the extent of the river reaches where flooding disasters may occur, such that counter-measures can be taken beforehand to reduce the natural disasters. 


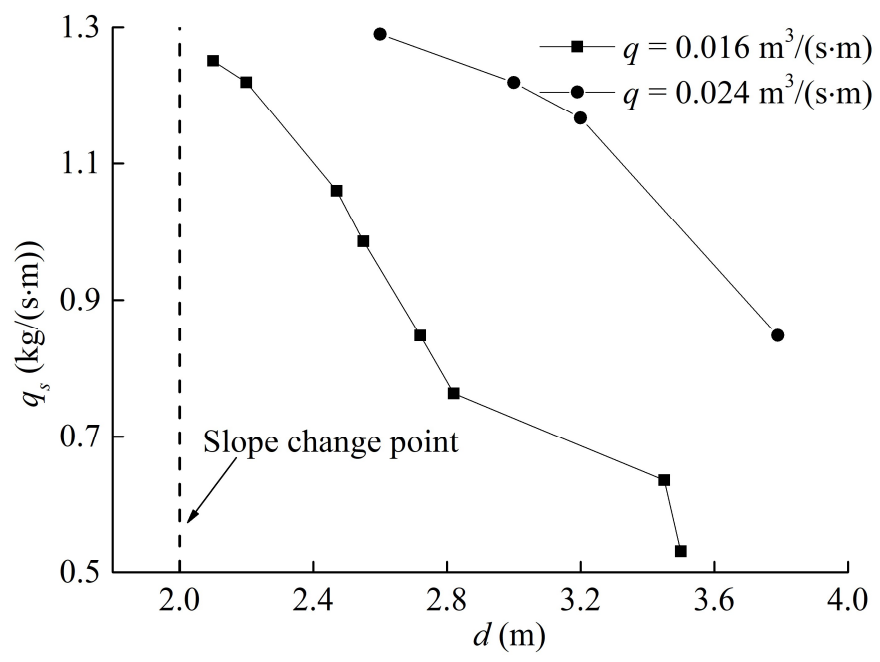

Figure 12 Initial siltation positions under different inflow discharges and sediment intensities

\section{Conclusions}

This paper studies the dynamic hydraulic jump in steep open channels under strong sediment transport condition and proposes a fluid-sediment interaction model in the framework of the SPH method. It is found that once the strong sediment transport over the steep slope is deposited in the lower reaches of steep slope, the adjustment of the local slope and the bed resistance may lead to the accumulation of sedimentation and its retrograde propagation. On being compared with the experimental results, the numerical simulations predicted key phenomena in the development of the dynamic hydraulic jump and the sedimentation, thus, proving the accuracy of the numerical model. Combining the numerical and experimental results, the parameter analysis on the critical triggering conditions was performed. It has been found that if the mountainous rivers receive sufficient sediment supply and reach the critical condition (i.e. the upstream-downstream slope ratio is higher than 2.0, and the sediment supply intensity is also 2.0 times higher than the maximum downstream sediment transport capacity), the retrograde sedimentation and retrograde propagation of the hydraulic jump can occur. This discovery is a counter-example of the traditional understanding that the downstream backwater cannot propagate upstream under the supercritical flow condition in the open channels.

Through parameter analysis, it was also found that during the retrograde sedimentation process, the development velocity of the siltation front and the initial siltation position are related to the sediment concentration of the flow. The lower the flow discharge and the higher the sediment supply intensity are, the faster is the development velocity of the siltation front, and closer is the initial siltation position to the upper reaches. The paper disclosed and analyzed a common situation where the water level increased abnormally in the mountainous rivers with a low flow discharge, and explained a phenomenon for which the traditional calculation method could not investigate appropriately. This is an important supplement to the existing mountainous river dynamics and provides a new guidance for the engineering design in view of the disaster prevention and mitigation.

Although the developed SPH model could predict the general characteristics of sedimentation in an open-channel flow, this model can be improved in the following aspects: (1) consider the constitutive relation of the sediment and the cohesion between sediment particles; (2) simulate the motion of real sediment particles (in the current model, the velocity of the sediment particles was obtained by interpolating the velocity of surrounding fluid particles); and (3) implement a proper turbulence model to reproduce the fluid turbulence associated with the dynamics hydraulic jump. These works are ongoing and will be published in future articles.

\section{Acknowledgements}

This research work is supported by the National Key Research and Development Program of China (No. 2016YFC0402302) and the National Natural Science Foundation of China (No.51609161). The authors appreciate the Open Funding SKHL1710 and SKHL1712 from the State Key Laboratory of Hydraulics and Mountain River Engineering in Sichuan University, China.

\section{References}

Antuono M, Colagrossi A, Marrone S, Molteni D (2010) Free-surface flows solved by means of SPH schemes with numerical diffusive terms. Computer Physics Communications 181: 532-549. http://dx.doi.org/10.1016/j.cpc.2009.11.002 
Aristodemo F, Tripepi G, Meringolo DD, Veltri P (2017) Solitary wave-induced forces on horizontal circular cylinders: Laboratory experiments and SPH simulations. Coastal Engineering 129: 17-35. http://dx.doi.org/10.1016/j.coastaleng.2017.08.011

Chen RD, Shao SD, Liu XN (2015) Water-sediment flow modeling for field case studies in Southwest China. Natural Hazards 78(2): 1197-1224. https://doi.org/10.1007/s11069-015-1765-Z

Chien N, Wan ZH (1999) Mechanics of sediment transport. ASCE(American Society of Civil Engineers) Press, USA.

De Padova D, Mossa M, Sibilla S, Torti E (2013) 3D SPH modelling of hydraulic jump in a very large channel. Journal of Hydraulic Research 51(2): 158-173. http://dx.doi.org/10.1080/o0221686.2012.736883

De Padova D, Mossa M, Sibilla S (2017) SPH numerical investigation of characteristics of hydraulic jumps. Environmental Fluid Mechanics. https://doi.org/10.1007/s10652-017-9566-4

Federico I, Marrone S, Colagrossi A, Aristodemo F, Antuono M (2012) Simulating 2D open-channel flows through an SPH model. European Journal of Mechanics 34(7): 35-46. https://doi.org/10.1016/j.euromechflu.2012.02.002

Gotoh H, Khayyer A (2018) On the state-of-the-art of particle methods for coastal and ocean engineering. Coastal Engineering Journal 6o(1): 79-103. https://doi.org/10.108o/21664250.2018.1436243

Guillén-Ludeña S, Franca MJ, Cardoso AH, Schleiss AJ (2016) Evolution of the hydromorphodynamics of mountain river confluences for varying discharge ratios and junction angles. Geomorphology 255: 1-15. https://doi.org/10.1016/j.geomorph.2015.12.006

Guo YK, Wu XG, Pan CH, Zhang JS (2012) Numerical simulation of the tidal flow and suspended sediment transport in the Qiantang Estuary. Journal of Waterway, Port, Coastal and Ocean Engineering 138(3): 192-202. https://doi.org/10.1061/(ASCE)WW.1943-5460.0000118

Hayashi M, Gotoh H, Sakai T, Ikari H (2003). Lagrangian gridless model of toe scouring of seawall due to tsunami return flow. Proceeding of the 2nd International Conference on Asian and Pacific Coast 2003, Makuhari, Japan.

Hosseini SM, Manzari MT, Hannani SK (2007) A fully explicit three-step SPH algorithm for simulation of non-Newtonian fluid flow. International Journal of Numerical Methods for Heat and Fluid Flow 17(7): $715-735$. https://doi.org/10.1108/09615530710777976

Jonsson P, Andreasson P, Hellström JGI, Jonsén P, Lundström TS (2016) Smoothed particle hydrodynamic simulation of hydraulic jump using periodic open boundaries. Applied Mathematical Modelling 40(19-20): 8391-8405. https://doi.org/10.1016/j.apm.2016.04.028

Khanpour M, Zarrati AR, Kolahdoozan M, Shakibaeinia A, Amirshahi SM (2016) Mesh-free SPH modeling of sediment scouring and flushing. Computers and Fluids 129: 67-78. https://doi.org/10.1016/j.compfluid.2016.02.005

Koshizuka S, Nobe A, Oka Y (1998) Numerical analysis of breaking waves using the moving particle semi-implicit method. International Journal for Numerical Methods in Fluids 26(7): 751-769. https://doi.org/10.1002/(SICI)10970363(19980415)26:7<751::AID-FLD671>3.0.CO;2-C

Liang QH, Borthwick AGL (2009) Adaptive quadtree simulation of shallow flows with wet-dry fronts over complex topography. Computers and Fluids 38(2): 221-234. https://doi.org/10.1016/j.compfluid.2008.02.008

Liu GR, Liu MB (2004) Smoothed particle hydrodynamics: a meshfree particle method. World Scientific, China. (In Chinese)

López D, Marivela R, Garrote L (2010) Smoothed particle hydrodynamics model applied to hydraulic structures: a hydraulic jump test case. Journal of Hydraulic Research 48(s1): 142-158. http://dx.doi.org/10.1080/00221686.2010.9641255

Manenti S, Sibilla S, Gallati M, Agate G, Guandalini R (2012) SPH simulation of sediment flushing induced by a rapid water flow. Journal of Hydraulic Engineering 138(3): 272-284. https://doi.org/10.1061/(ASCE)HY.1943-7900.0000516

Meringolo DD, Colagrossi A, Marrone S, Aristodemo F (2017) On the filtering of acoustic components in weakly-compressible SPH simulations. Journal of Fluids and Structures 70: 1-23. http://dx.doi.org/10.1016/j.jfluidstructs.2017.01.005

Monaghan JJ (1994) Simulating free surface flows with SPH. Journal of Computational Physics 110(2): 399-406. https://doi.org/10.1006/jcph.1994.1034

Nabian MA, Farhadi L (2016) Multiphase mesh-free particle method for simulating granular flows and sediment transport. Journal of Hydraulic Engineering 143(4): 04016102. https://doi.org/10.1061/(ASCE)HY.1943-7900.0001275

Pitlick J, Recking A, Liebault F (2013) Linkages between sediment supply and channel morphology in gravel-bed river systems. European Geosciences Union General Assembly 2013, Vienna, Austria.

Shakibaeinia A, Jin YC (2011) A mesh-free particle model for simulation of mobile-bed dam break. Advances in Water Resources 34(6): 794-807. https://doi.org/10.1016/j.advwatres.2011.04.011 
Shao SD, Lo EYM (2003) Incompressible SPH method for simulating Newtonian and non-Newtonian flows with a free surface. Advances in Water Resources 26: 787-800. https://doi.org/10.1016/So309-1708(03)ooo30-7

Spinewine B (2005) Two-layer flow behaviour and the effects of granular dilatancy in dam break induced sheet-flow. PhD thesis, Univerisité de Louvain.

Sun PN, Ming FR, Zhang AM (2015) Numerical simulation of interactions between free surface and rigid body using a robust SPH method. Ocean Engineering 98: 32-49. https://doi.org/10.1016/j.oceaneng.2015.01.019

Wang D, Shao SD, Li SW, Shi Y, Arikawa T, Zhang HQ (2018) 3D ISPH erosion model for flow passing a vertical cylinder. Journal of Fluids and Structures 78: 374-399. https://doi.org/10.1016/j.jfluidstructs.2018.01.003

Xia JQ, Falconer RA, Lin BL, Tan GM (2011) Numerical assessment of flood hazard risk to people and vehicles in flash floods. Environmental Modelling and Software 26(8): 987-998. https://doi.org/10.1016/j.envsoft.2011.02.017

Zhang RJ (1961) River dynamics. China Industry Press, China. (In Chinese)

Zhang ZL, Liu MB (2018) A decoupled finite particle method for modeling incompressible flows with free surfaces. Applied Mathematical Modelling 60: 606-633. https://doi.org/10.1016/j.apm.2018.03.043

Zhu HJ, Qi X, Lin PZ, Yang YC (2013) Numerical simulation of flow around a submarine pipe with a spoiler and current-induced scour beneath the pipe. Applied Ocean Research 41(6): 87-100. https://doi.org/10.1016/j.apor.2013.03.005 